\title{
Transformation of Levantine Intermediate Water tracked by MEDARGO floats in the Western Mediterranean
}

\author{
M. Emelianov ${ }^{1}$, J. Font ${ }^{1}$, A. Turiel ${ }^{1}$, C. Millot ${ }^{2}$, J. Solé ${ }^{1}$, P.-M. Poulain ${ }^{3}$, A. Julià ${ }^{1}$, and M.-R. Vitrià ${ }^{1}$ \\ ${ }^{1}$ Institut de Ciències del Mar - CSIC, Passeig Marítim de la Barceloneta, 37-49, 08003 Barcelona, Spain \\ ${ }^{2}$ Laboratoire d'Océanographie et de Biogéochimie, Antenne LOB-COM-CNRS, BP330, 83507 La Seyne sur Mer, France \\ ${ }^{3}$ Instituto Nazionale di Oceanografia e di Geofisica Sperimentale (OGS), Borgo Grotta Gigante, 42c, 34010 Trieste, Italy
}

Received: 3 April 2006 - Published in Ocean Sci. Discuss.: 20 June 2006

Revised: 10 November 2006 - Accepted: 29 November 2006 - Published: 8 December 2006

\begin{abstract}
A clustering methodology is applied to investigate the thermohaline structure of Levantine Intermediate Water (LIW) in the western Mediterranean basin. Sixteen freedrifting hydrographic profilers were deployed in the framework of the MFSTEP project (MEDARGO component) from September 2003. A total of 925 CTD profiles collected up to the beginning of February 2006 have been used in the analysis. The results are in good agreement with the general circulation scheme for intermediate waters in the basin and confirm the hypothesis about a "discrete-continuous" thermohaline structure of LIW.
\end{abstract}

\section{Introduction}

Levantine Intermediate Water (LIW), the saltiest intermediate Mediterranean water mass, is formed in the eastern basin, more especially in the northern part of the Levantine subbasin, south of Rhodes mainly (see e.g. Ovchinnikov et al., 1976; Hopkins, 1978). After sinking to its equilibrium depth, LIW spreads and circulates before outflowing from the eastern basin into the western one through the channel of Sicily. In spite of being relatively easily tracked in all Mediterranean sub-basins, some details of LIW thermohaline characteristics, modification processes, and circulation still require to be better understood (Millot, 2005). The most accepted LIW circulation scheme in the western basin was first proposed by Millot (1987): LIW entering through the channel of Sicily mainly circulates cyclonically through the successive western sub-basins as a geostrophic vein following the continental slope due to the Coriolis effect, although affected by the intense mesoscale activity typical of the Mediterranean Sea. A well-known sign of the presence of LIW in a CTD profile is maxima of temperature (relative) and salinity (abso-

Correspondence to: $\mathrm{M}$. Emelianov

(mikhail@icm.csic.es) lute) encountered everywhere at depths of 200-600 m. The erosion of these maxima indicates LIW transformation, by mixing with surrounding waters, during its alongslope circulation in the western basin, although sometimes less transformed waters are observed further west than the most transformed ones, especially in the Algerian sub-basin. The interior of this sub-basin is generally filled with relatively old and strongly transformed LIW that has not escaped the western basin through the strait of Gibraltar and is somehow resident there. Volumes of new LIW just entered from the eastern sub-basin can be pulled away from the slope of Sardinia and transported toward the sub-basin interior, i.e. westwards, by mesoscale features (in particular Algerian Eddies) passing by (Emelianov et al., 2000; Millot and Taupier-Letage, 2005).

However, this may not be the only reason for the disagreement between the observed spatial distribution of LIW $\theta$-S (potential temperature - salinity) properties in the Mediterranean, and what should be predicted by models of a continuously transformed and isopycnically circulating layer (Bubnov, 1967). In 1985 the hypothesis of a "discretecontinuous" spatial structure of LIW (Emelianov and Fedorov, 1985) was proposed. Based on the analysis of observations and taking into account the "non-uniform character" of LIW formation, it was proposed that the LIW layer can be thought of as an "emulsion". According to this idea, the emulsion consists of background water with high temperature and salinity; in which lenses and sheets of even more saltier and warmer waters will be dispersed. The background layer is initially formed by LIW, sunk down to the corresponding isopycnal level in its formation region before circulating at intermediate depths. New volumes of LIW, generated due to density increasing by cooling in winter of water salinizied in summer due to evaporation in the surface layer, continue to sink down to the depth of the isopycnal level of this background water (Ovchinnikov et al., 1976). These saltier and warmer volumes of LIW are eventually broken into smaller ones by mixing processes, mainly of double

Published by Copernicus GmbH on behalf of the European Geosciences Union. 
Table 1. MEDARGO floats status (8 February 2006).

\begin{tabular}{|c|c|c|c|c|c|c|c|c|c|c|}
\hline $\mathrm{N}^{\circ}$ & Model & $\begin{array}{l}\text { WMO } \\
\text { code }\end{array}$ & Deploy date & Lat & Lon & Cycle & Last date & Lat & Lon & Status* \\
\hline 1 & APEX & 6900226 & 26 Sep 2003 15:25 & 41.75 & 3.72 & 12 & 7 Nov 2003 15:30 & 41.16 & 3.62 & $\mathrm{R}$ \\
\hline 2 & APEX & 6900227 & 26 Sep 2003 15:06 & 41.73 & 3.72 & 6 & 11 Nov 2003 07:24 & 41.32 & 2.26 & $\mathrm{R}$ \\
\hline 3 & PROVOR & 6900228 & 2 Oct 2003 17:27 & 41.60 & 3.77 & 10 & 7 Nov 2003 15:30 & 41.17 & 3.81 & $\mathrm{R}$ \\
\hline 4 & PROVOR & 6900229 & 2 Oct 2003 18:33 & 41.60 & 3.73 & 5 & 7 Nov 2003 15:32 & 41.28 & 3.92 & $\mathrm{R}$ \\
\hline 5 & APEX & 6900278 & 30 June 2004 13:43 & 41.61 & 3.94 & 77 & 30 June 2005 14:01 & 37.40 & -1.40 & $\mathrm{D}$ \\
\hline 6 & APEX & 6900279 & 30 June 2004 12:18 & 41.75 & 3.82 & 105 & 8 Oct 2005 11:11 & 39.47 & 3.29 & $\mathrm{D}$ \\
\hline 7 & APEX & 6900280 & 16 Aug 2004 10:00 & 38.85 & 12.97 & 108 & 7 Feb 2006 11:12 & 41.75 & 11.29 & A \\
\hline 8 & APEX & 6900281 & 15 Aug 2004 20:08 & 39.61 & 12.42 & 107 & 6 Feb 2006 21:20 & 41.35 & 11.36 & A \\
\hline 9 & APEX & 6900282 & 15 Aug 2004 10:46 & 40.17 & 11.98 & 106 & 6 Feb 2006 09:57 & 38.89 & 9.36 & A \\
\hline 10 & PROVOR & 6900291 & 7 Sep 2004 02:14 & 41.68 & 6.10 & 82 & 19 Oct $200506: 41$ & 42.10 & 8.12 & $\mathrm{D}$ \\
\hline 11 & PROVOR & 6900292 & 7 Sep 2004 08:32 & 40.67 & 6.10 & 104 & 7 Feb 2006 07:44 & 40.92 & 4.75 & A \\
\hline 12 & PROVOR & 6900293 & 7 Sep 2004 15:23 & 39.65 & 7.12 & 104 & 6 Feb 2006 06:28 & 42.30 & 7.00 & A \\
\hline 13 & PROVOR & 6900294 & 8 Sep 2004 04:27 & 38.63 & 7.12 & 72 & 5 Sep 2005 07:24 & 38.42 & 13.36 & $\mathrm{D}$ \\
\hline 14 & PROVOR & 6900295 & 26 Oct 2004 09:15 & 37.86 & 0.68 & 30 & 22 March 2005 08:22 & 37.58 & 5.30 & $\mathrm{D}$ \\
\hline 15 & APEX & 6900300 & 27 Sep 2005 10:45 & 41.17 & 2.61 & 26 & 4 Feb 2006 12:50 & 38.45 & 0.30 & A \\
\hline 16 & $\begin{array}{l}\text { PROVOR } \\
\text { Total }\end{array}$ & 4900556 & 22 March 2005 23:54 & 41.59 & 4.61 & $\begin{array}{l}64 \\
1018\end{array}$ & 8 Feb 2006 01:21 & 36.14 & -1.19 & $\mathrm{~A}$ \\
\hline
\end{tabular}

*R - Recovered, D - Dead, A - Alive

diffusion nature (Ruddick and Turner, 1979). The smallest lenses dissipate, and then contribute to maintain the high temperature and salinity of the background layer. However, this picture is complicated by the involvement of LIW in the formation of all other Mediterranean water masses and the the effects of mesoscale circulation.

The free-drifting hydrographic profiling floats launched in the western basin in the framework of the MFSTEP project (contribution to MEDARGO, the Mediterranean component of the international ARGO program) provided new data that allow monitoring the complex LIW thermohaline structure and its dynamics throughout the period of observation (Poulain, 2005; Poulain et al., 2006).

\section{Materials and methods}

CTD data from 16 profiling floats (eight APEX from Webb Research Corporation, Falmouth, USA, and eight PROVOR from Martec Serpe-Iesm, Guidel, France, see e.g. Davis et al., 1992; Loaec et al., 1999) operating in the western Mediterranean from September 2003 until the beginning of February 2006 (Table 1) were downloaded from the ARGO Global Data Assembly Centre (GDAC), also known as CORIOLIS Operational Oceanography Data Centre or the MFSTEP Archiving and Dissemination Data Center (ADDC) (http://www.coriolis.eu.org/cdc/ projects/cdcMFSTEPFloats.asp).

The profilers control their own buoyancy and execute identical programmed 5-day long cycles. They drift at a parking depth of $350 \mathrm{db}$ for 4.5 days, then descent to $700 \mathrm{db}(2000 \mathrm{db}$ every 10 cycles) to start ascending to the surface while col- lecting temperature and conductivity measurements with a Sea-Bird Electronics CTD probe. Once at surface, data are transmitted by satellite ARGOS link for few hours, and the floats finally descent again to the parking depth. For the APEX, shallow and deep profiles include 80 and 106 sampling depths, respectively, spanning the water column with intervals of $5 \mathrm{~m}$ above $100 \mathrm{~m}, 10 \mathrm{~m}$ between 100 and $700 \mathrm{~m}$, and $50 \mathrm{~m}$ below $700 \mathrm{~m}$. For the PROVOR, 71 sampling depths were programmed between 5 and $705 \mathrm{~m}$, with $10-\mathrm{m}$ intervals, and 26 depths between 725 and $1975 \mathrm{~m}$ (50-m interval). See Poulain et al. (2006) for more details. During the study period a total of 1018 profiling cycles produced 925 usable CTD profiles.

A first analysis of the resulting $\theta$-S curves (potential temperature - salinity) of all the downloaded profiles was performed using Ocean Data View software (Schlitzer, 2004). This showed that the LIW cores are within a range of 200 to $500 \mathrm{db}$ in pressure and 29.0 to 29.1 in sigma- $\theta$, a typical fact for the western Mediterranean, and that there is a wide range of thermohaline maxima $\left(13.1<\theta<14.35^{\circ} \mathrm{C}\right.$ and $38.49<\mathrm{S}<38.76$ ) associated with different shapes of $\theta-\mathrm{S}$ curves (Fig. 1).

Objective cluster analysis (Kaufman and Rousseeuw, 1990) was used to classify the ensemble of LIW $\theta$-S curves to unveil classes of differently transformed waters. This type of analysis (also known as segmentation analysis or taxonomy analysis) seeks to identify homogeneous subgroups in a given population. Cluster analysis allows the identification of a set of groups that both minimize within-group variation and maximize between-group variation. Hierarchical clustering is based on defining a distance between elements, 

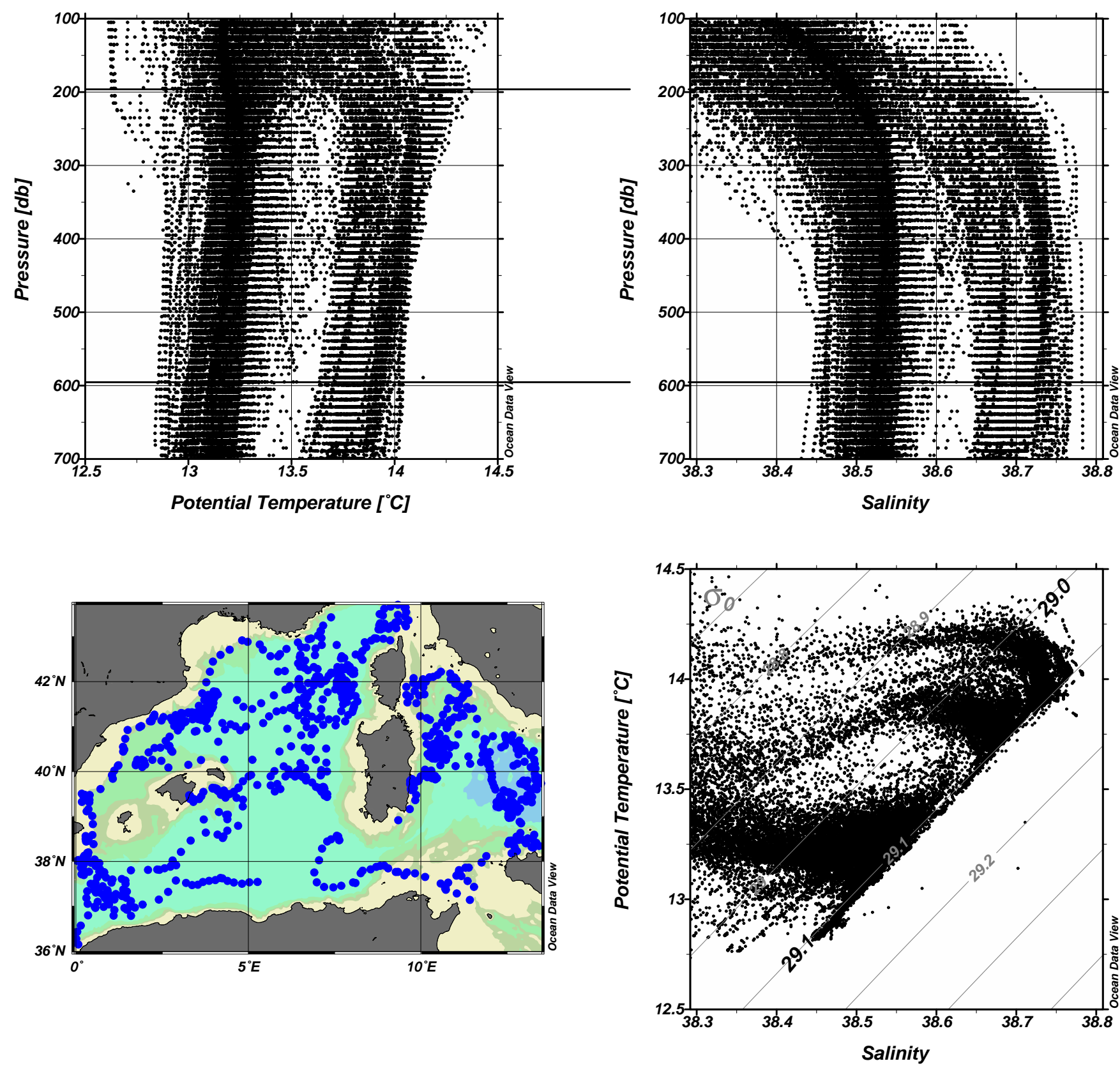

Fig. 1. Floats position, profiles in the $100-700$ dbar range, and corresponding $\theta-\mathrm{S}$ curves during all the observation period. Light colour marks the continental shelf and slope area (until $500 \mathrm{~m}$ ).

selecting a linking method to form the clusters, and finally determining how many clusters best suit to the data. A particular type of hierarchical clustering is K-means clustering, in which one specifies the number $\mathrm{K}$ of clusters in advance, and then calculates how to assign cases to the K clusters. We have applied a modified version of the K-means clustering methodology, in which instead of specifying the number of clusters we specify the maximum cluster radius in the $\theta-\mathrm{S}$ diagram. We obtained the clusters by successively extracting the most representative or central $\theta-\mathrm{S}$ curve for each cluster (that is, the one which has the maximum number of other $\theta$-S curves at a distance smaller or equal to the maximum radius). The clustering process is finished when the whole set of $\theta$-S curves is classified, or when only additional small statistically non-significant clusters are obtained. The value of the maximum radius was selected by comparison of $\theta$ $S$ curves obtained in different parts of the western Mediterranean (Emelianov et al., 2000).

We need first to define a reasonable notion of distance in the $\theta$-S diagram. Given two sets of values $\left(\theta_{0}, S_{0}\right)$ and $\left(\theta_{1}\right.$, 

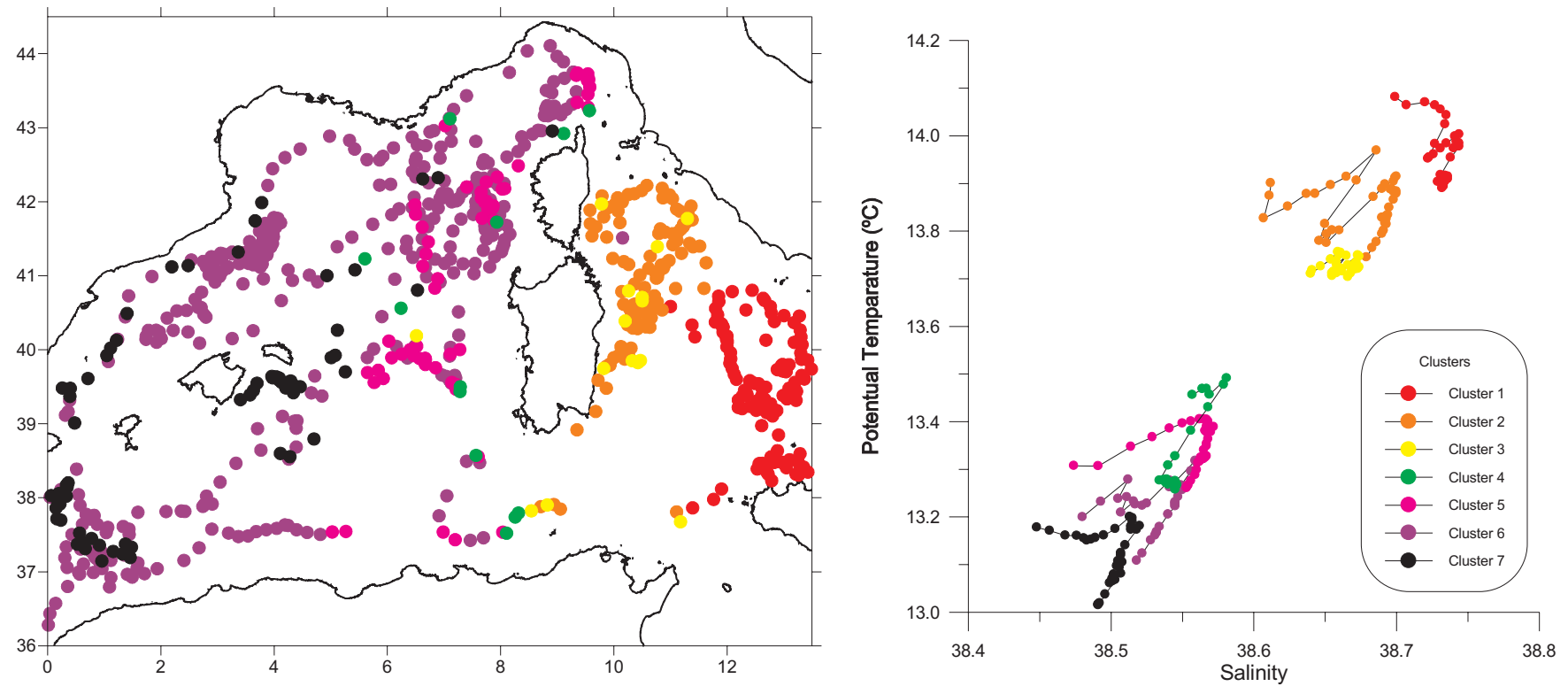

Fig. 2. Left: Float positions, colour marked according to the cluster they belong to.

Right: Representative $\theta$-S curves for the 7 clusters obtained during the first iteration.

$S_{1}$ ), in the $\theta$-S diagram, we define the distance between them as:

$d\left(\left(\theta_{0}, S_{0}\right),\left(\theta_{1}, S_{1}\right)\right)=\left[\left(\theta_{0}-\theta_{1}\right)^{2}+k^{2}\left(S_{0}-S_{1}\right)^{2}\right]^{1 / 2}$

where the factor $\kappa$ is the temperature-to-salinity aspect ratio and is expressed in ${ }^{\circ} \mathrm{C} / \mathrm{psu}$. We have conventionally fixed $\kappa$ to $4^{\circ} \mathrm{C} / \mathrm{psu}$, which means that a separation of 1 psu can be considered equivalent to a separation of $4^{\circ} \mathrm{C}$. We extend the point-to-point distance to a point-to-curve distance in the following way: given a point $\left(\theta_{0}, S_{0}\right)$ and a curve $\mathrm{p}=\left\{\left(\theta_{i}, S_{i}\right)\right.$, $\mathrm{i}=1, \ldots, \mathrm{N}\}$, the distance $\mathrm{d}\left(\left(\theta_{0}, S_{0}\right), \mathrm{p}\right)$ is given by

$d\left(\left(\theta_{0}, S_{0}\right), p\right)=\min _{i} d\left(\left(\theta_{0}, S_{0}\right)\right),\left(\left(\theta_{i}, S_{i}\right)\right)$

Finally, the distance between two curves $\mathrm{p}=\left\{\left(\theta_{i}, S_{i}\right)\right.$, $\mathrm{i}=1, \ldots, \mathrm{N}\}$ and $\mathrm{q}=\left\{\left(\theta_{j}, S_{j}\right), \mathrm{j}=1, \ldots, \mathrm{M}\right\}$ is defined as:

$d(p, q)=\min \left(\frac{1}{N} \sum_{i} d\left(\left(\theta_{i}, S_{i}\right), q\right), \frac{1}{M} \sum_{j} d\left(\left(\theta_{j}, S_{j}\right), p\right)\right)(3)$

We proceed to classify the $\theta$-S curves observed within the LIW core pressure range through two stages. First, the core pressure was determined as the average pressure between that of the absolute maximum of salinity and that of the closest relative maximum of potential temperature. Once this core pressure is determined, we have extracted the data included in a \pm 200 -db range. This is done in a curve-by-curve basis, so that for each $\theta$-S curve, only the LIW core pressure is taken into account whatever this pressure is.

In the first stage, a maximum radius $r=0.05^{\circ} \mathrm{C}$ was applied. This radius implies that, to be included in the same cluster,
$\theta$-S curves may differ at most in $\theta$ by $0.05^{\circ} \mathrm{C}$ or in $\mathrm{S}$ by 0.0125 from the central $\theta$-S curve. In the second iteration, $\mathrm{K}$-clustering was applied only to those $\theta$-S-curves belonging to the largest cluster (Cluster 6) and the radius was reduced to the half, $\mathrm{r}=0.025^{\circ} \mathrm{C}$. Thus, in this case $\theta$-S curves with $\Delta \theta>0.025^{\circ} \mathrm{C}$ and $\Delta \mathrm{S}>0.00625$ were separated in different clusters.

We were concerned that sensors drift could dramatically affect the clustering results, especially in the case of small searching radius, and consequently all the CTD data was analysed to detect any possible drift effect (Wong et al., 2003). MEDARGO floats CTD data downloaded from the CORIOLIS data centre is from real time process (data mode is "R") with ARGO real time quality control (Wong et al., 2005). Delayed mode process (Wong et al., 2003) has not yet been done at CORIOLIS. The average working period for the floats we have analysed is $6 \pm 4$ months. The difference between the first deep profile and all consecutive deep profiles in the deepest layer of the cast (1450-2000 db) was calculated for all deep profiles (those programmed until $2000 \mathrm{db}$ ) from the floats that worked more than 6 months. We did not encounter any systematical changes in salinity values that could be interpreted as a drift. The magnitude of the differences was of order $10^{-3}$, the values being smaller when the float returned constantly to the same deep water mass and larger when it drifted into different water masses. These salinity differences do not affect the clustering because the searching radius is one order larger $(0.0125)$. In case of subclustering the searching radius is 0.00625 is comparable to the obtained salinity differences. But the clustering tool analyses the salinity profile together with the temperature one 

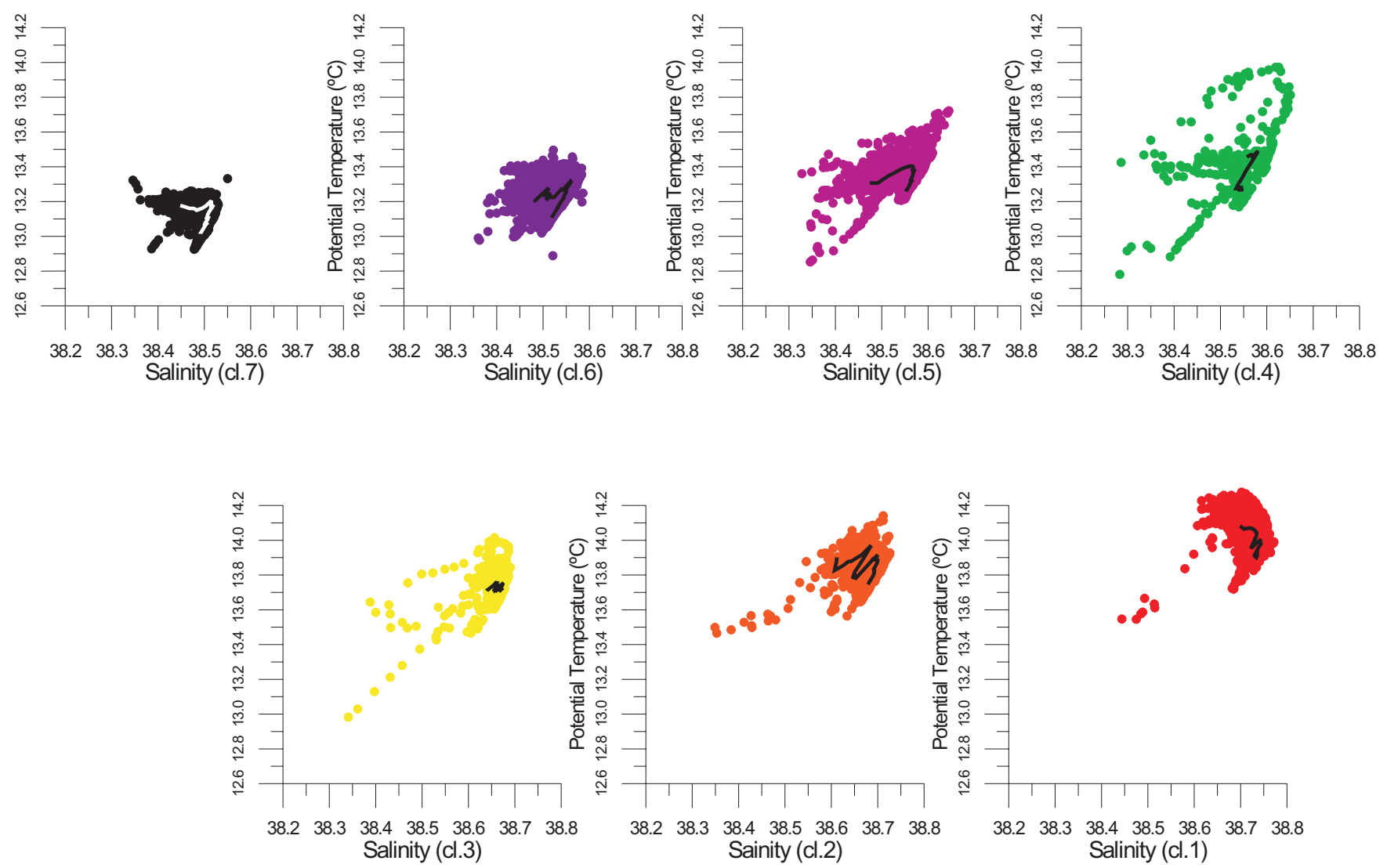

Fig. 3. Representative $\theta$-S curves enveloped in all $\theta$-S curves of the same cluster. First iteration: Maximum radius $\mathrm{r}=0.05^{\circ} \mathrm{C}$. $\theta$-S curves differ in $\theta$ by $0.05^{\circ} \mathrm{C}$ or in $\mathrm{S}$ by 0.0125 from the central $\theta-\mathrm{S}$ curve.

(sub-clustering searching radius is $0.025^{\circ} \mathrm{C}$ ). Thus a possible drift in salinity data would be "neutralized" with the temperature, in the sense that if there was not a significant drift in temperature (and this is not the case) the $\theta-S$ curves would not be erroneously attributed to a different sub-cluster. They would create instead a new sub-cluster, shifted in salinity but not in temperature. The performed analysis allows us to conclude that the real time quality controlled MEDARGO data are good enough to be used in clustering.

\section{Results and discussion}

As a result of the first iteration seven clusters were obtained (Fig. 2). The clusters are ranked and coloured according to the degree of LIW transformation (the higher cluster numbers and "cold" colours correspond to more transformed LIW, and clusters with less transformed LIW have smaller cluster number and "warm" colours). The representative $\theta$ $\mathrm{S}$ curves of each of the seven clusters are their "centres of mass" in the $\theta-S$ diagram.

The representative $\theta-\mathrm{S}$ curves identified among all $\theta-\mathrm{S}$ curves of the same cluster provide the differences between $\theta$ -
S curves within each cluster and differences between "neighbouring" $\theta-\mathrm{S}$ curves belonging to different clusters (Fig. 3).

In Fig. 2 one can see three main groups of clusters, represented by their centres of mass. Clusters 1, 2 and 3 are situated in the saltier and warmer part of the $\theta-\mathrm{S}$ diagram, so corresponding to the saltiest LIW located in the Tyrrhenian sub-basin. Less saline cluster representatives 5, 6 and 7 include the $\theta$-S curves in the interior of the Provençal and Algerian sub-basins, mainly away from the continental slope (of Corsica and Sardinia islands as well as of the mainland).

$\theta-\mathrm{S}$ curves included in cluster 4 lie in the channel of Sardinia area and in the central part of the Provençal and Algerian sub-basins between Sardinia and Menorca Islands marking the transition between less transformed LIW from the eastern part of the analysed area and more transformed LIW from the western part of the western Mediterranean basin. The $\theta-\mathrm{S}$ curves belonging to the largest cluster (number 6) are encountered everywhere west of Corsica and Sardinia, and they should be considered as the background LIW in terms of the Emelianov and Fedorov hypothesis. Less transformed LIW from cluster 5 (mostly near to the expected path of the northwards vein that circulate around the two islands after exiting the Tyrrhenian) and more eroded one 


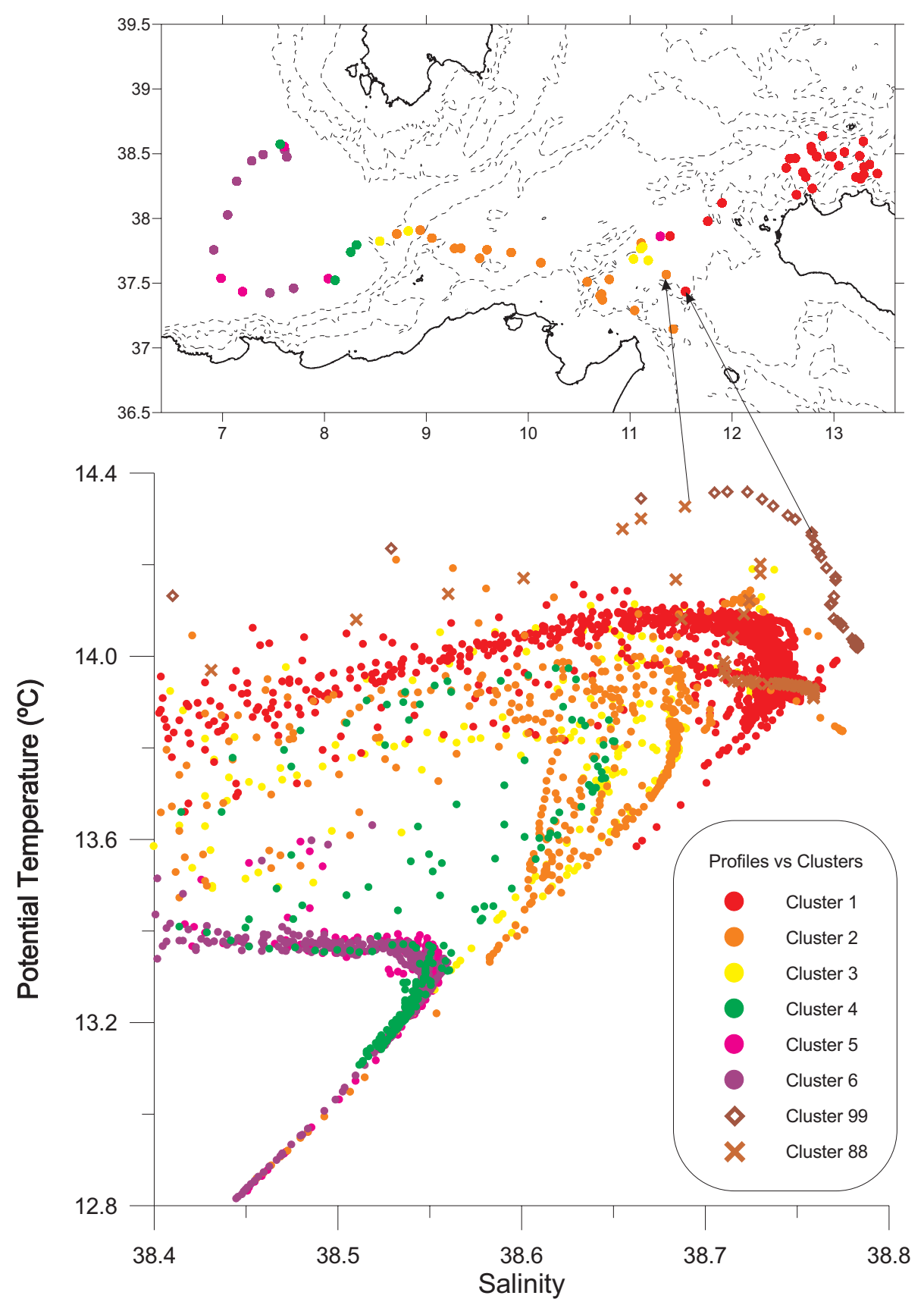

Fig. 4. Float PROVOR 6900294 trajectory and $\theta$-S curves.

from cluster 7 (in the westernmost part of the basin, where the main LIW vein is expected to have followed the continental slope until flowing the Balearic islands or crossed the channel between them and the mainland) are embedded into the area occupied by the background LIW from cluster 6 . An interesting fact is that some floats sampled differently transformed LIW in consecutive casts. This means that the floats did not park at the same portion of LIW and that their trajectories were significantly affected by surface drift, during their periodic ascent, surfacing and descent motions to transmit data by satellite link.
We illustrate this with a couple of examples (Figs. 4 and 5), where we grouped the set of $\theta-\mathrm{S}$ curves for a single float in different clusters on the $\theta$-S diagram. The clearest example is float 6900294 (Fig. 4), which crossed the channel of Sardinia moving eastwards, and sampled transformed LIW from clusters 6 (background) and 5 then intermediate stages (cluster 4) and less transformed LIW, situated north of Tunisia coast (clusters 3 and 2), in the channel of Sicily area (cluster 2) and finally in the Tyrrhenian (cluster 1). Taking into account the LIW circulation scheme from Millot (1999) this float, during its surfacing, was advected to the channel of 


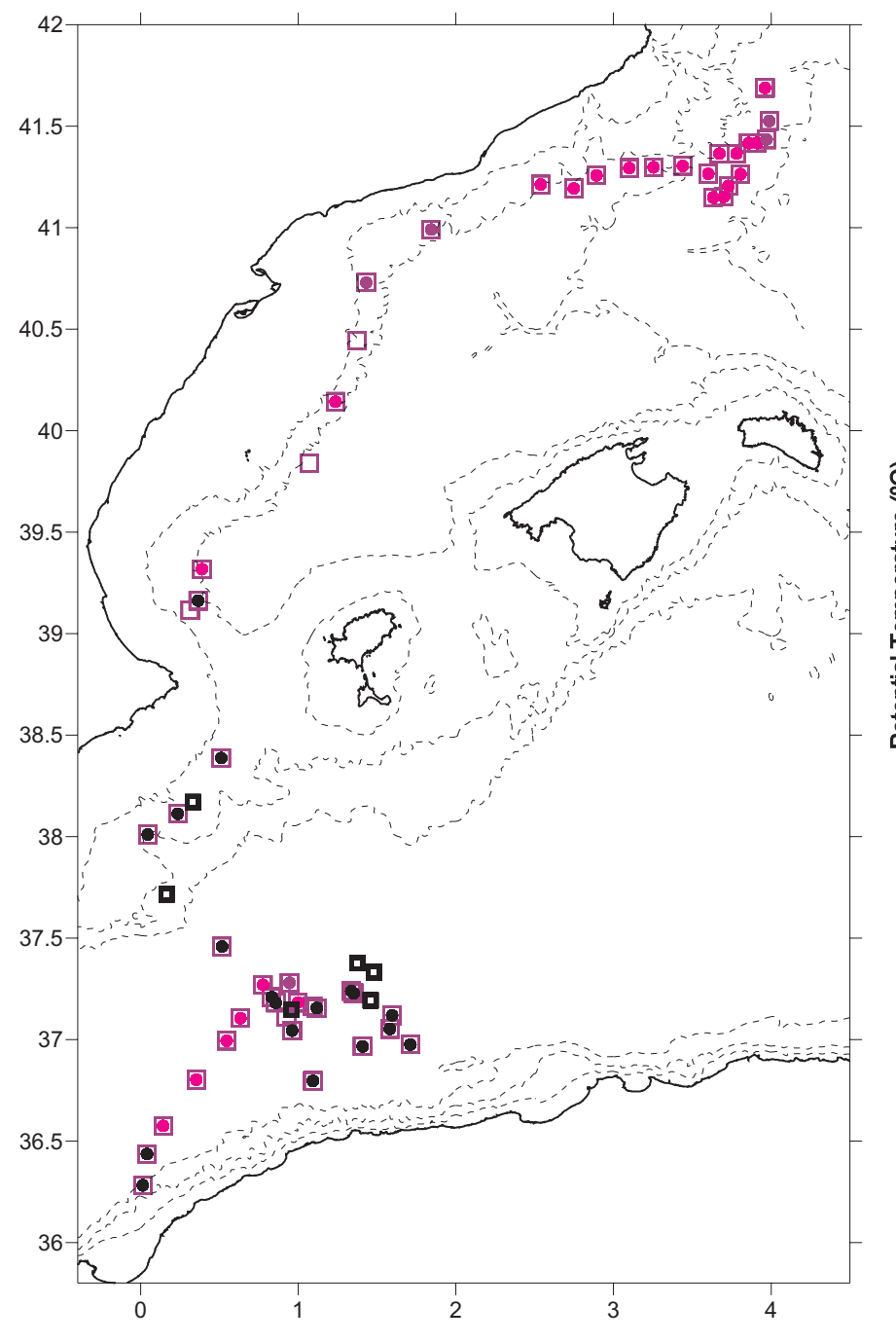

Fig. 5. Float APEX 6900278 trajectory and $\theta$-S curves.

Sicily by the Algerian current, probably after being trapped by a large mesoscale eddy around $38^{\circ} \mathrm{N}$ (clusters $4,5,6$ ), and then re-entered the Tyrrhenian sub-basin maybe due to the bifurcation of the surface current system that takes place in this area (Font at al., 1998), until sampling the less transformed LIW (cluster 1) north of Sicily, where LIW recently entered from the eastern Mediterranean is expected to be found. During this trajectory the float sampled the saltiest LIW situated in the narrowest part of the channel of Sicily, in the western sill (two $\theta$-S curves that were not assigned to any cluster, here labelled as cluster 88 and 99), just when the float was re-entering the Algerian sub-basin after having drifted to the south. The $\theta$-S curve from these casts is relatively uniform and does not have the thermohaline inhomogeneities often observed above and below LIW core in other areas of the basin. These peculiarities are mainly formed by the processes of mixing and stirring of LIW with surrounded water masses. This demonstrates the important

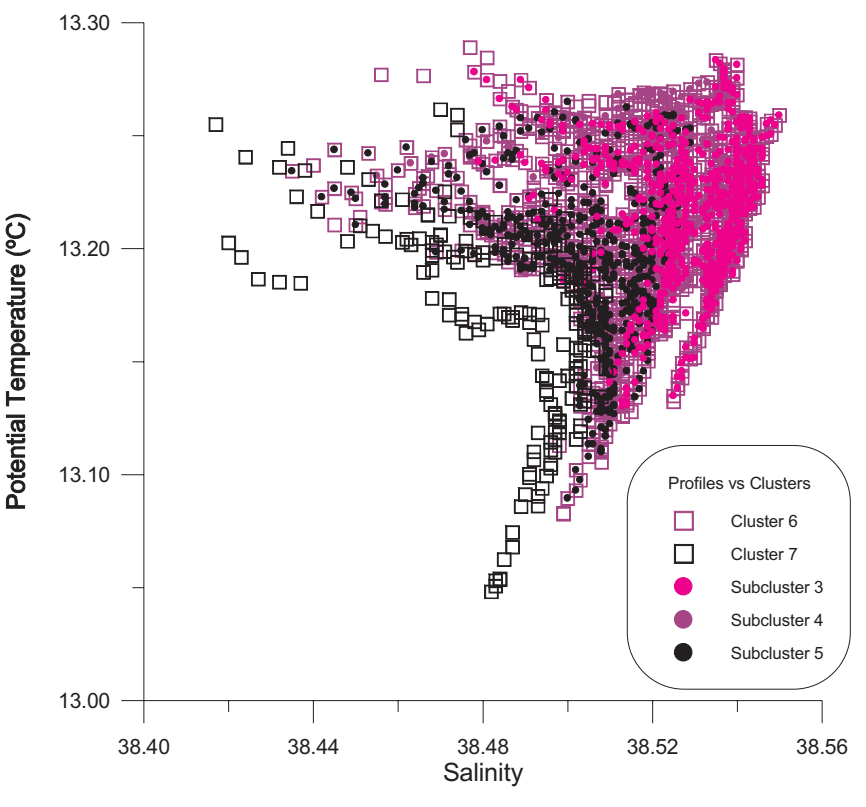

role of Mediterranean straits in modifying the thermohaline structure (Astraldi et al., 1999) and confirms the hypothesis about the "focusing effect" of the straits (Emelianov and Fedorov, 1985) that suggests that in the narrowest parts of the channels and above the sills, the mixing processes are more intense, and this leads to homogenization of LIW and to destruction of warmer and saltier lenses. After crossing the channel area, as current velocities decrease, the "emulsion of LIW" returns to be separated into continuous (background layer) and dispersed (saltier and warmer lenses) phases. The thermohaline inhomogeneities begin to appear on $\theta$-S curves due to double-diffusive mixing, which tends to diminish the remaining excesses of salt and heat (Kelley, 2001).

Another example of changes in the LIW $\theta$-S structure is presented in Fig. 5. In this case, float 6900278 drifted southward along the Spanish continental slope, sampling LIW from sub-clusters of cluster 6 (background). At the end of that trajectory, close to the Algerian coast, the float sampled 

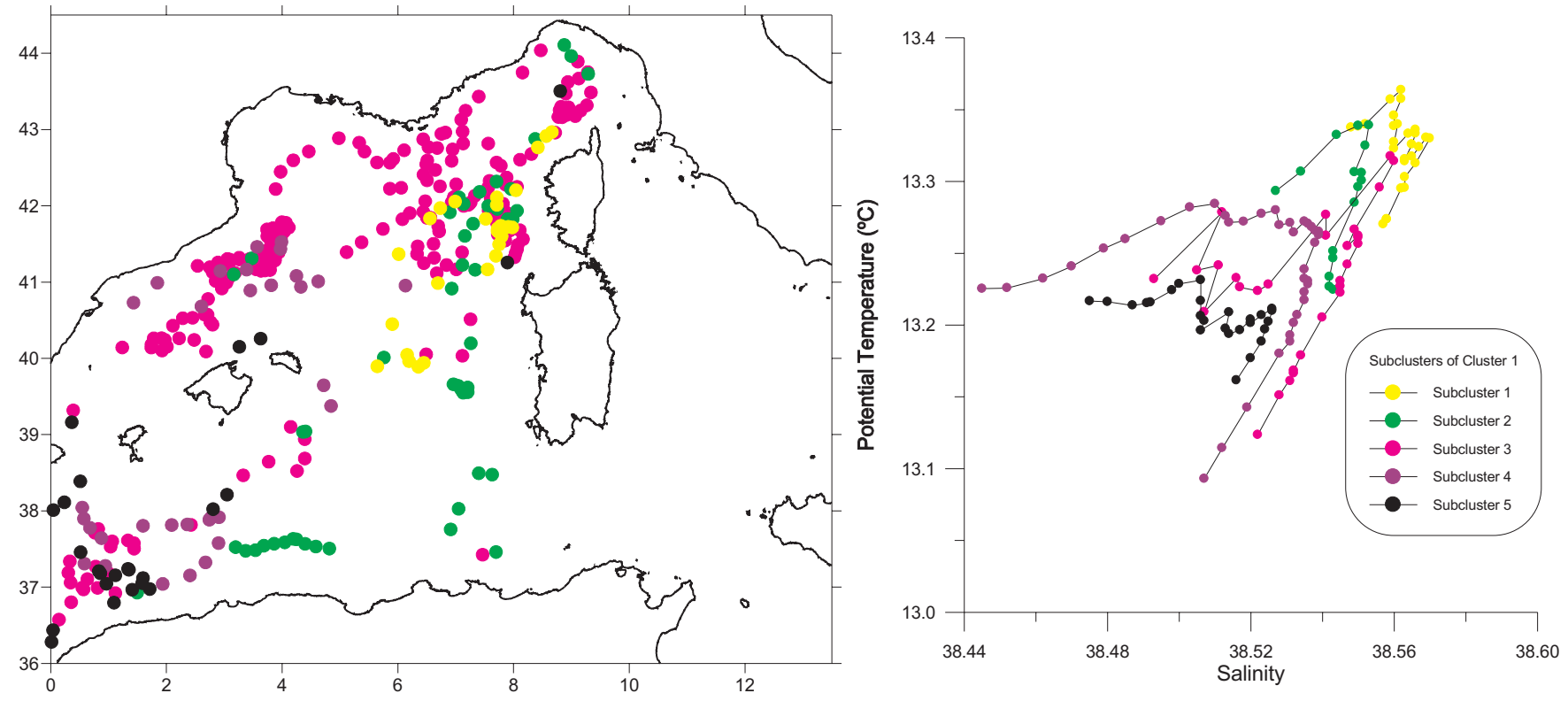

Fig. 6. Left: Positions of Cluster 1 floats, colour marked according to the sub-cluster they belong to.

Right: Representative $\theta$-S curves for the 5 sub-clusters obtained during the second iteration.
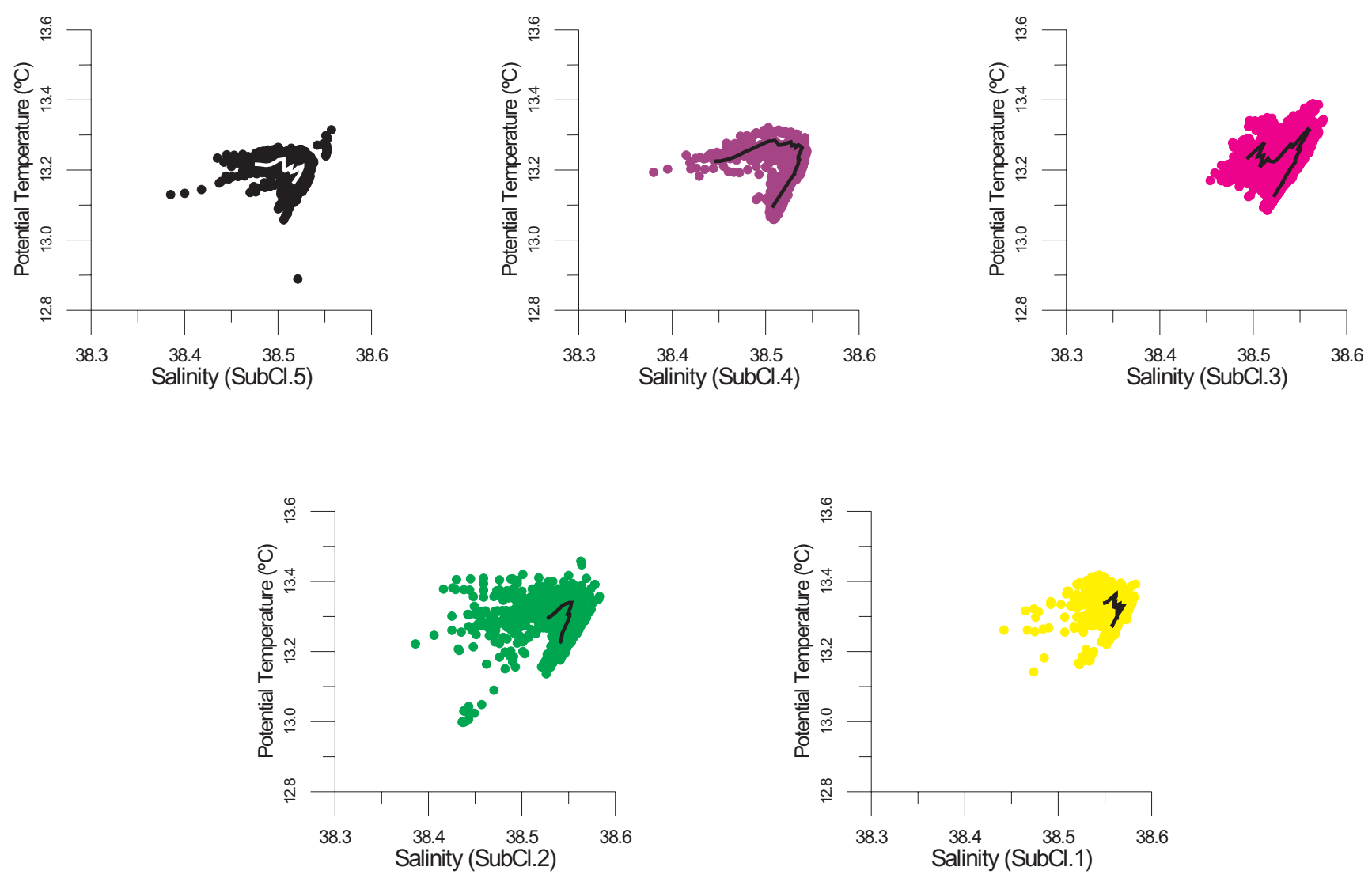

Fig. 7. Representative $\theta$-S curves enveloped in all $\theta$-S curves of the same sub-cluster. Second iteration: Maximum radius $\mathrm{r}=0.025^{\circ} \mathrm{C}$. $\theta-\mathrm{S}$ curves differs in $\mathrm{q}$ by $0.025^{\circ} \mathrm{C}$ or in $\mathrm{S}$ by 0.00625 from the central $\theta-\mathrm{S}$ curve. 
more transformed LIW from cluster 7 and three sub-clusters of cluster 6. This float displays a "classical" behaviour, following the vein of LIW that circulates alongslope while progressively eroding its T-S signature.

The second iteration of K-clustering was applied just on $\theta-\mathrm{S}$ curves of the largest cluster 6 with the search radius reduced to a half $(\mathrm{r}=0.025)$, in order to reveal subtler differences in the $\theta$-S curves included in this class. As the result of the second iteration, Cluster 6 was split into five sub-clusters (Fig. 6). As shown in the figure, the spatial distribution of sub-clusters has a spotty character. The representative $\theta$-S curves enveloped in all $\theta$-S curves of the same sub-cluster, provide, as in the case of clusters, the differences between $\theta$-S curves within each sub-cluster and differences between "neighbouring" $\theta$-S curves belonging to different sub-clusters (Fig. 7). Consecutive $\theta-\mathrm{S}$ curves sampled by the same float show that less transformed LIWs very often incorporate more transformed ones. This situation can be explained from the point of view of the "discrete-continuous" structure of this water. During its displacement, the float samples different parts of a continuously-transforming background layer, so encountering different volumes of LIW with different values of temperature and salinity.

It is necessary to note that our analysis does not consider the time component; we just analyzed the spatial $\theta$-S variability of LIW. Probably, taking into account time variability it will be possible to provide a better track on the spatial distribution of differently transformed $\theta$-S curves and hence to reduce the degree of patchiness observed in the subclassification of background layer waters, represented by the largest cluster.

\section{Conclusions}

The clustering method used to analyze the $\theta-\mathrm{S}$ curves in the western Mediterranean basin allowed classifying in a canonical, automatic way the spatial distribution of differently transformed LIW. According to the interpretation of LIW proposed by Emelianov and Fedorov (1985), the characteristic $\theta$-S curve associated to background LIW defines the largest class of similar (i.e., close) $\theta$-S curves, with the largest range of temperature and salinity differences. We have also shown that differently transformed intermediate waters were embedded into this background but at specific, different geographical areas of the basin.

When the class defining the background is studied in further detail by reducing the allowed cluster radius, we observe that the new classes of $\theta$-S curves present a spotty character in spatial distribution of differently transformed LIW.

The obtained results are in good agreement, so can be considered as a confirmation, with the Emelianov-Fedorov hypothesis about "discrete-continuous" thermohaline structure of Levantine Intermediate Water. They also confirm the general LIW alongslope cyclonic circulation pattern proposed by
Millot for the Mediterranean, with disturbing effects that can be due to interaction with mesoscale eddies in the southern part of the basin mainly.

Another conclusion, evidenced in the case shown in Fig. 4, is that the MEDARGO profiling cycle (reduced to 5 days from the standard ARGO 10 day cycle so as to optimize the requirements for data assimilation in the MFSTEP operational model) reduces the quality of the submerged $(350 \mathrm{~m})$ velocity information. The displacements they undergo while ascending through upper water layers, while at the surface transmitting data, and while descending again to the parking depth (total of 8-12h) can have a stronger influence on the horizontal float motion than the time they remain in the generally slower currents at the subsurface parking depth. This reduces the probability that a float returns to the same water mass that it left at the start of its ascent.

Acknowledgements. This work is a contribution to the EU project MFSTEP (EUK3-2001-00174), and to the Spanish project ESEOO (VEM2003-20577-C14). A. Turiel is supported by a Ramón y Cajal contract by the Spanish Ministry of Education.

Edited by: D. Webb

\section{References}

Astraldi, M., Balopoulos, S., Candela, J., Font, J., Gacic, M., Gasparini, G. P., Manca, B., Theocaris, A., and Tintoré, J.: The role of straits and channels in understanding the characteristics of Mediterranean circulation, Progress in Oceanography, 44, 65108, 1999.

Bubnov, V. A.: Vertical turbulent exchange and transformation of Mediterranean waters in the Atlantic Ocean, Oceanology, 7(4), 586-592, 1967.

Davis, R. E., Webb, D. C., Regier, L. A., and Dufour, J.: The Autonomous Lagrangian Circulating Explorer (ALACE), J. Atmos. Oceanic Technol., 9, 264-285, 1992.

Emelianov, M. V. and Fedorov, K. N.: Structure and Transformation of Intermediate Waters of the Mediterranean Sea and Atlantic Ocean, Oceanology, 25(2), 155-161, 1985.

Emelianov, M., Millot, C., Font, J., and Taupier-Letage, I.: New data on Levantine Intermediate Water circulation in the western Mediterranean sea. In: Oceanic fronts and related phenomena, UNESCO Workshop Report No. 159, ISBN 5-89118-155X, 132-137, 2000.

Font, J., Millot, C., Salas, J., Julia, A., and Chic, O.: The drift of Modified Atlantic Water from the Alboran Sea to the eastern Mediterranean, Scientia marina., 68(3), 331-342, 1998.

Hopkins, T. S.: Physical processes in the Mediterranean basin, in: Estuarine transport processes, edited by: Kjerfe, B., Univ. South California Pres., 269-310, 1978.

Kaufman, L. and Rousseeuw, P. J.: Finding groups in data: An introduction to cluster analysis NY, John Wiley \& Sons, ISBN 0471878766, 1990.

Kelley, D. E.: Six questions about double-diffusive convection, in: Fom stirring to mixing in a stratified ocean: 12th 'Ana Huliko' a Hawaiian winter Workshop, edited by: Müller, P. and Garret, C., Univ. of Hawaii, 2001. 
Loaec, G., Carval, T., Le Reste, S., and Maudire, G.: Provor and Coriolis Data Center: a step towards operational oceanography, Data Buoy Conference Panel Workshop, 1999.

Loaec, G., Le Reste, S., Le Bras, S., Gac, C., Marchese, F., Bouquet, P., and Deuff, A.: Les flotteurs profileurs: état de la technologie et perspectives d'utilisation, http://www.ifremer.fr/dtmsi/ produits/marvor/aei2004_fFlotteursProfileurs_110304.pdf, 2004.

Millot, C.: Circulation in the Western Mediterranean, Oceanol. Acta, 10(2), 143-149, 1987.

Millot, C.: Circulation in the Western Mediterranean sea, J. Mar. Systems, 20(1-4), 423-442 1999.

Millot, C.: Circulation in the Mediterranean Sea: evidences, debates and unanswered questions, Scentia Marina, 69(1), 5-21, 2005.

Millot, C. and Taupier-Letage, I.: Additional evidence of LIW entrainment across the Algerian Basin by mesoscale eddies and not by a permanent westward-flowing vein, Progress in Oceanography, 66(2-4), 231-250, 2005.

Ovchinnikov, I. M., Plakhin, E. A., Moskalenko, L. B., Neglyad, K. V., Osadchyi, A. C., Fedoseev, A. F., Krivosheya, V. G., and Voitova, K. V.: Hydrology of Mediterranean Sea, Gidrometeoizdat (in Russian), 375, 1976.
Poulain, P.-M.: MEDARGO: A profiling Float program in the Mediterranean, Argonautics, 6, 2, 2005.

Poulain, P.-M., Barbanti, R., Font, J., Cruzado, A., Millot, C., Gertman, I., Griffa, A., Molcard, A., Rupolo, V., Le Bras, S., and Petit de la Villeon, L.: MEDARGO: a drifting profiler program in the Mediterranean Sea, Ocean Sci. Discuss., 3, 1901-1943, 2006, http://www.ocean-sci-discuss.net/3/1901/2006/.

Ruddick, B. R. and Turner, J. S.: The vertical scale of doublediffusive intrusions, Deep-Sea Res., 26, 8A, 903-914, 1979.

Schlitzer, R.: Ocean Data View, http://www.awi-bremerhaven.de/ GEO/ODV, 2004.

Wong, A. P. S., Johnson, G. C., and Owens, W. B.: Delayed-mode calibration of Autonomous CTD profiling float salinity data by Theta-S climatology, J. Atmos. Oceanic Technol., 20(2), 308318, 2003.

Wong, A., Keeley, R., Carval, T., and the Argo Data Management Team: Argo data management. Quality control manual, ver. 2.1, http://www.coriolis.eu.org/cdc/argo/ argo-quality-control-manual.pdf, 2005 